\title{
SKUTECZNOŚĆ OSŁON PRZECIWSŁONECZNYCH W KSZTALTOWANIU KOMFORTU CIEPLNEGO W PASYWNYM BUDYNKU UŻYTECZNOŚCI PUBLICZNEJ
}

\begin{abstract}
W artykule przeanalizowano wpływ osłon przeciwsłonecznych na komfort cieplny w pasywnym budynku użyteczności publicznej. Dokonano porównania warunków środowiska wewnętrznego w badanym obiekcie bez zastosowania odpowiednich ochron oraz z uwzględnieniem rolet zacieniających oraz żaluzji wielkogabarytowych. Okres letni oraz jest niezwykle trudny do utrzymania komfortu termicznego w obiektach pasywnych. Wyeksponowanie budynków o dużej powierzchni przeszkleń na działanie promieni słonecznych może mieć bardzo negatywne skutki dla człowieka. Zyski od znajdujących się w budynku źródeł ciepła, $\mathrm{w}$ połączeniu $\mathrm{z}$ wysoką temperaturą zewnętrzną mogą łatwo doprowadzić do przegrzania i zachwiania równowagi cieplnej organizmu. Zaburzenia procesów termoregulacji, objawiające się między innymi wzrostem temperatury skóry, przyspieszeniem oddechu, rozszerzeniem naczyń krwionośnych, zwiększeniem częstości skurczów serca czy zachwianiem gospodarki wodnej i elektrolitycznej organizmu mogą doprowadzić do osłabienia, nudności i zawrotów głowy. Celem przeprowadzonym analiz jest wskazanie racjonalnego zastosowania osłon w celu zapewnienia korzystnego mikroklimatu wewnątrz. Narzędziem do przeprowadzenia analizy termicznej jest program Design Builder, stanowiący interface do programu symulacyjnego budynków Energy Plus, utworzonego na zlecenie rządu USA. Z przeprowadzonych analiz wynika, iż z uwagi na warunki środowiskowe we wnętrzu hali najkorzystniejsze będzie zastosowanie zarówno zewnętrznych łamaczy światła jak i wewnętrznych rolet. Należy jednak zwrócić uwagę na to, że osłony po stronie wewnętrznej powinny być opuszczane tylko w momencie dużego nasłonecznienia, przy wysokich temperaturach powietrza zewnętrznego.
\end{abstract}

Słowa kluczowe: łamacze światła, rolety wewnętrzne, wskaźnik PMV, zyski słoneczne

1 Mgr inż. Anna Dudzińska, Zakład Budownictwa i Fizyki Budowli, Wydział Inżynierii Lądowej, Politechnika Krakowska, ul. Warszawska 24, Kraków, tel. 12 628-23-84, email: anna.dudzinska27@gmail.com 


\section{Wstęp}

Znacząca potrzeba ograniczenia zysków słonecznych w okresach wysokich temperatur zewnętrznych dla budynków pasywnych skłania do stosowania w nich różnych rozwiązań konstrukcyjnych. Wymagania techniczno-użytkowe dotyczące przegród przeszklonych zostały określone w rozporządzeniu ministra infrastruktury w sprawie warunków technicznych, jakim powinny odpowiadać budynki i ich usytuowanie [3]. Przegrzewające się latem pomieszczenia stwarzają spore problemy ekonomiczne i eksploatacyjne. Osłony pełnią kluczową funkcję w kształtowaniu korzystnych warunków środowiska wewnętrznego oraz wpływają na energooszczędność budynku.

Systemy osłon przeciwsłonecznych, jako nieodzowny element powierzchni przeszklonych, mają za zadanie kontrolować ilość promieni słonecznych docierających do wnętrza budynku. Regulację ilości światła oraz dostarczanej enregii zapewniają między innymi żaluzje, rolety i łamacze światła, znajdujące sie po wewnętrznej lub zewnętrznej stronie. Miejsce ich montażu, wielkość oraz nachylenie wpływają na skuteczność ochrony przed promieniowaniem [4].

$\mathrm{W}$ poddanej analizie hali sportowej na elewacji południowej zastosowano, zamontowane w pozycji poziomej, nieruchome żaluzje wielkogabarytowe, czyli tzw. łamacze światła (rysunek 1).

Aluminiowe przesłony uniemożliwiają przenikanie bezpośredniego promieniowania słonecznego do wnętrza budynku przy wysokim położeniu słońca. Stałe łamacze światła nie dają jednak możliwości dostosowywania warunków oświetlenia do aktualnych potrzeb dlatego zastosowano dodatkowo rolety wewnętrzne. Ten popularny system zabezpieczeń niestety ogranicza dostępność światła naturalnego oraz uniemożliwia kontakt wizualny ze środowiskiem zewnętrznym.

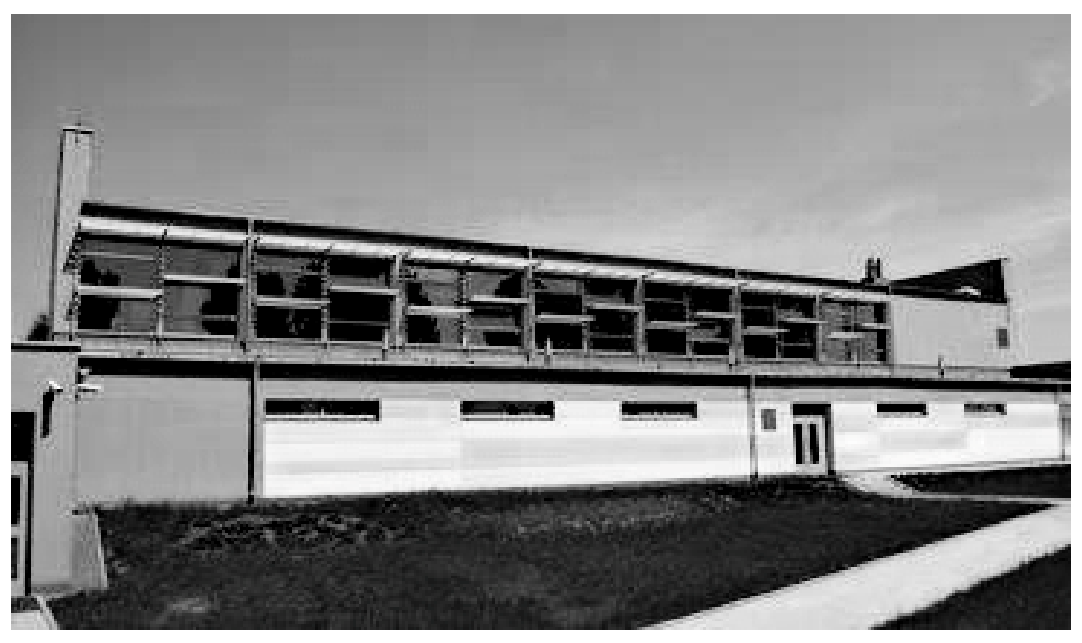

Rys. 1. Łamacze światła na elewacji południowej (archiwum autorki)

Fig. 1. Overhang on south elevation 


\section{Komfort cieplny}

Komfort cieplny jest ważnym elementem pozytywnego odbioru warunków środowiska $w$ danym pomieszczeniu. Definiowany jest on jako stan równowagi pomiędzy ilością ciepła, powstającego w organizmie w czasie przemian metabolicznych, a stratami ciepła oddawanego do środowiska między innymi na drodze promieniowania, konwekcji i przewodzenia [1].

Jednym z podstawowych wskaźników do oceny komfortu termicznego jest PMV (Predictive Mean Vote). Określa on przewidywaną ocenę średnią zgodnie z siedmiostopniową psychofizyczną skalą wrażeń cieplnych Fangera [1].

Tabela 1. Siedmiostopniowa skala oceny środowiska umiarkowanego, na podstawie [1]

Table 1. Scale of the medium environment, based on [1]

\begin{tabular}{|c|c|c|}
\hline+3 gorąco & & -1 dość chłodno \\
\hline+2 ciepło & 0 obojętnie & -2 chłodno \\
\hline+1 dość ciepło & & -3 zimno \\
\hline
\end{tabular}

W normie PN-EN ISO 7730:2006 [2] przyjęte są trzy klasy komfortu cieplnego, w zależności od założonego poziomu wymagań. Analizowana hala jest obiektem o wymaganiach średnich, dla których zaleca się, aby wartość PMV znajdowała się w przedziale od $-0,5$ do $+0,5$.

\section{Założenia przyjęte do modelowania w programie Design Builder}

Analizę termiczną przeprowadzono przy pomocy programu Design Builder. Dane geometryczne rozpatrywanego budynku hali starano się dokładnie odwzorować w kwestii kształtu, wymiarów obiektu oraz rozmieszczenia otworów. Model hali w programie Design Builder przedstawiają rysunki 2 i 3.

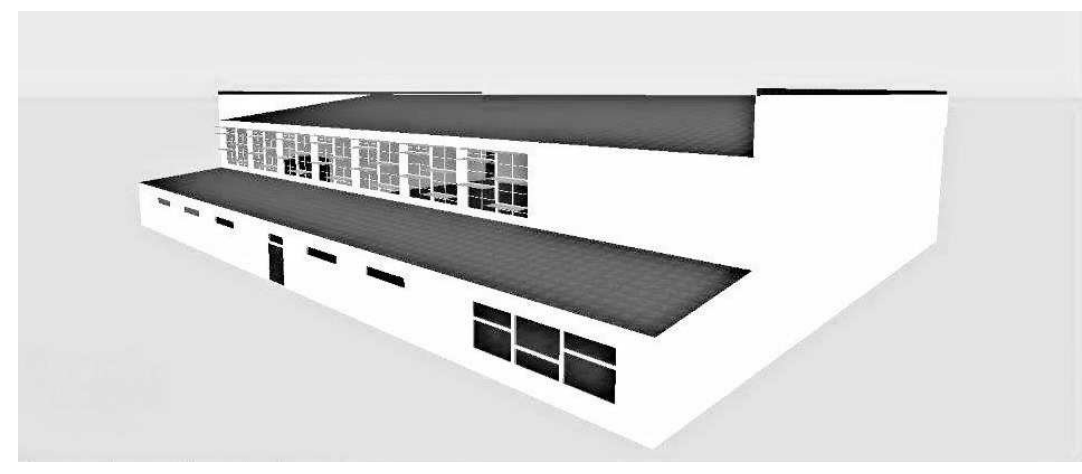

Rys. 2. Elewacja południowa hali

Fig. 2. South elevation of the sports hall building 


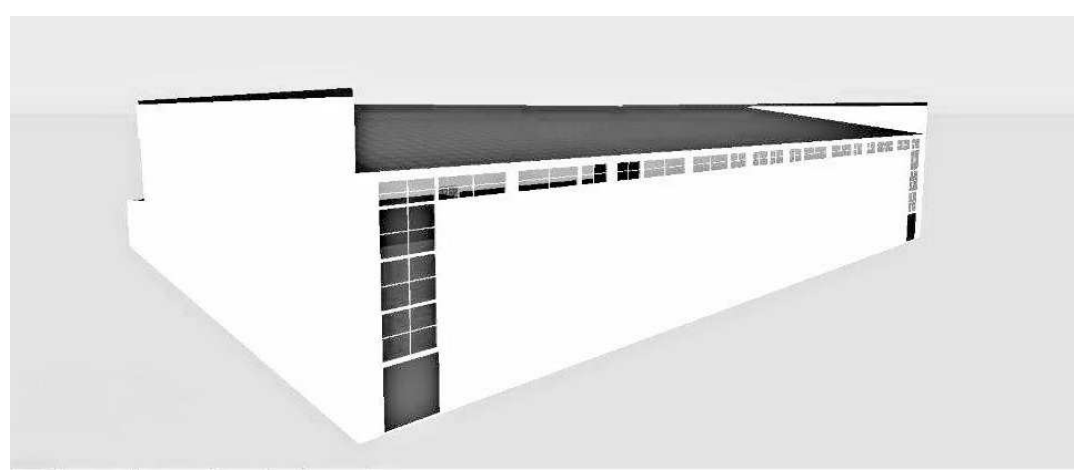

Rys. 3. Elewacja północna hali

Fig. 3. North elevation of the sports hall building

Opracowany model hali umożliwił odwzorowanie zjawisk cieplnych zachodzących w budynku rzeczywistym. W programie uwzględniono charakterystyki przeźroczystych i nieprzeźroczystych przegród budowlanych, infiltracje powietrza zewnętrznego, zyski od wewnętrznych źródeł ciepła oraz instalacje.

Zgodnie z projektem, założono łamacze światła o wysięgu jednego metra. Przyjęto, że rolety wewnętrzne opuszczane są po osiągnięciu temperatury powietrza zewnętrznego równej $24^{\circ} \mathrm{C}$.

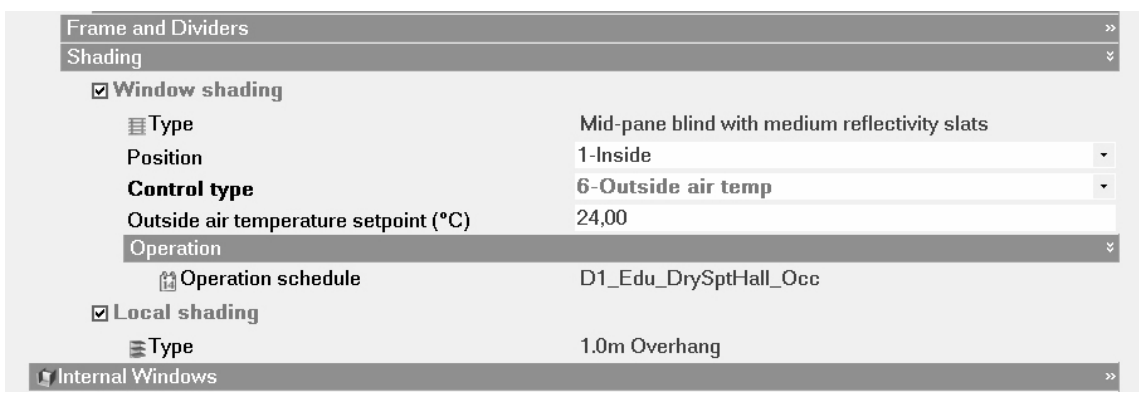

Rys. 4. Założenia przyjęte w modelowaniu dotyczące rolet wewnętrznych

Fig. 4. Foundations received in modelling

Symulacje przeprowadzono dla okresu od 1 maja do 30 sierpnia, ze względu na występowanie wówczas najwyższych temperatur zewnętrznych. Modyfikacjom poddano elewacje południową i wykonano cztery symulacje dla następujących wersji:

- podstawowa - bez zastosowania łamaczy światła oraz rolet zacieniających,

- z zastosowaniem łamaczy światła, bez rolet zacieniających,

- bez łamaczy światła, z roletami zacieniajacymi,

- z łamaczami swiatła i roletami zacianiającymi. 


\section{Analiza uzyskanych obliczeń symulacyjnych}

Przeprowadzone badania pozwalają sformułować wnioski, dotyczące skuteczności zastosowanych rozwiązań chroniących budynek przed przegrzewaniem oraz ich wpływu na komfort cieplny w pasywnej hali podczas okresu wysokich temperatur zewnętrznych.

Rozkład wskaźnika PMV dla czteromiesięcznej analizy symulacyjnej przedstawiono na rys. 5, a obliczone wartości wskaźników przewidywanej oceny średniej podano na rys. 6. Biorąc pod uwagę wartość średnią wskaźnika PMV najbardziej korzystne jest zastosowanie łamaczy światła, ale bez rolet wewnętrznych. Wskaźnik przewidywanej oceny średniej wynosi w tym wypadku 0,83 i jest najbliższy przedziałowi komfortu podanemu przez Fangera [1].

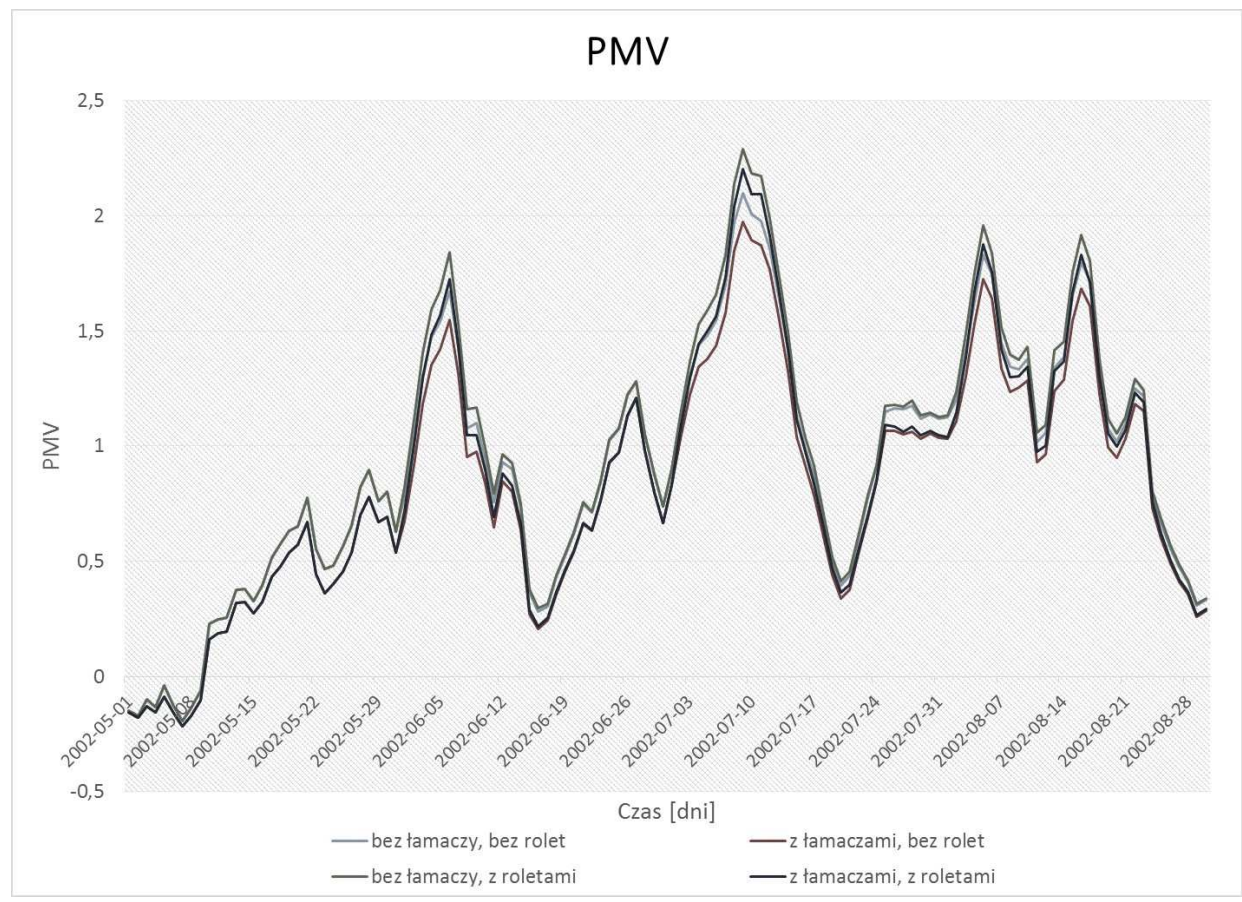

Rys. 5. Rozkład wskaźnika PMV dla analizowanych opcji zabezpieczeń przeciwłonecznych

Fig. 5. PMV coefficient for four simulation cases 


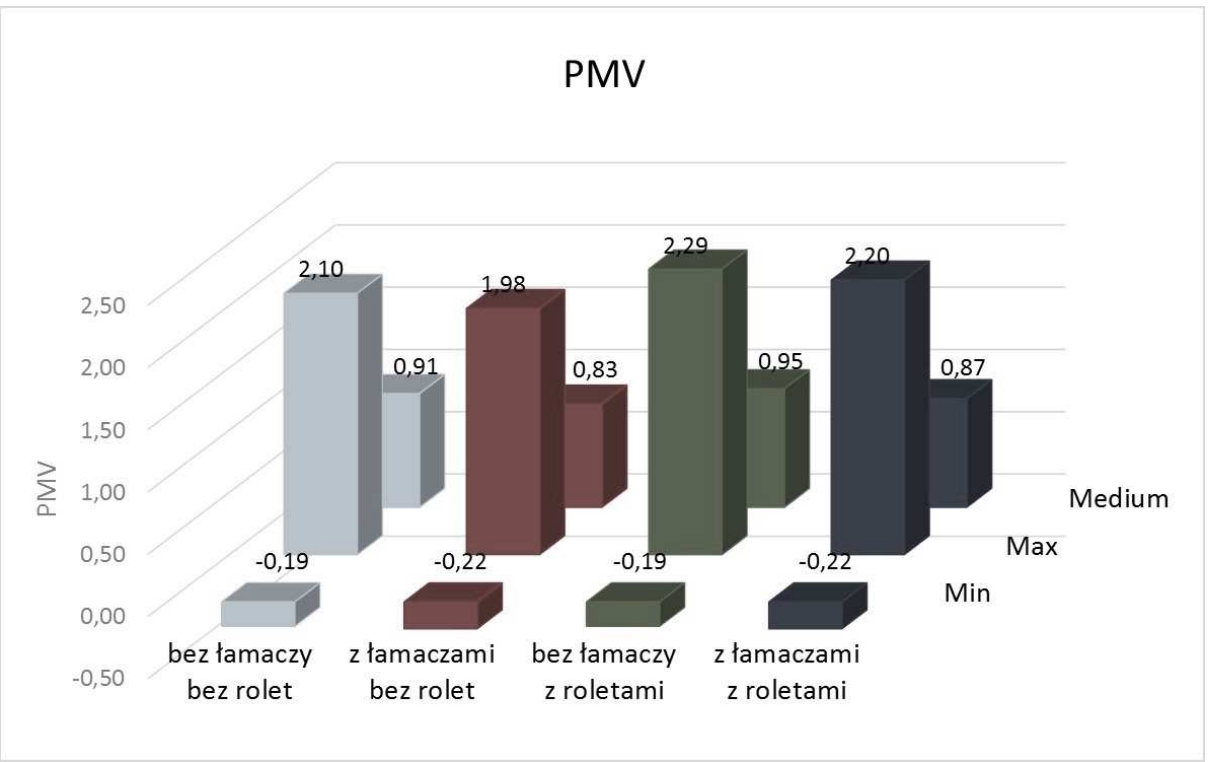

Rys. 6. Minimalne, maksymalne i średnie wartości wskaźnika PMV dla całego okresu analizy

Fig. 6. Min, max and medium values PMV coefficient for four simulation cases

Najmniej korzystny układ osłon dotyczy sytuacji, w której zastosowano tylko rolety wewnętrzne, bez zewnętrznych łamaczy światła. Średnia wartość wskaźnika PMV wynosi wówczas 0,95 , a maksimum wynosi 2,29 . Tylko w wariancie drugim, kiedy korzysta się tylko z zewnętrznych osłon, maksymalna wartość PMV nie przekracza wartości progowej wynoszącej 2,0. Nie można mówić wówczas o komforcie cieplnym, a jedynie o obciążeniu termicznym dającym się tolerować lub nie i należałoby sprawdzić wskaźnik WBGT dla tych przypadków.

Tabela 2. Wartości temperatur wewnętrznych dla całego okresu analizy

Table 2. Air temperature values for the whole pariod of the analysis

\begin{tabular}{|l|c|c|c|c|}
\hline$\left[{ }^{\circ} \mathbf{C}\right]$ & $\begin{array}{l}\text { Bez lamaczy, } \\
\text { bez rolet }\end{array}$ & $\begin{array}{l}\text { Z lamaczami, } \\
\text { bez rolet }\end{array}$ & $\begin{array}{l}\text { Bez lamaczy, } \\
\mathbf{z} \text { roletami }\end{array}$ & $\begin{array}{l}\mathbf{Z} \text { lamaczami, } \\
\mathbf{z} \text { roletami }\end{array}$ \\
\hline Min & 15,09 & 15,07 & 15,09 & 15,07 \\
\hline Max & 26,20 & 25,68 & 27,28 & 26,87 \\
\hline Medium & 20,44 & 20,07 & 20,64 & 20,29 \\
\hline
\end{tabular}

Temperatura powietrza w hali osiąga wartość największą w przypadku zastosowania jedynie osłon wewnętrznych i wynosi $27,28^{\circ} \mathrm{C}$. Średnie temperatury również w tym przypadku są najwyższe. Najniższa średnia wartość temperatury wewnątrz wynosi $20,07^{\circ} \mathrm{C}$ i występuje w momencie kiedy zainstalowane są tylko łamacze światła. 
Tabela 3. Wartości wilgotności wewnątrz hali dla całego okresu analizy

Table 3. Humidity values for the whole pariod of the analysis

\begin{tabular}{|l|c|l|l|l|}
\hline$[\%]$ & $\begin{array}{l}\text { Bez lamaczy, } \\
\text { bez rolet }\end{array}$ & $\begin{array}{l}\text { Z lamaczami, } \\
\text { bez rolet }\end{array}$ & $\begin{array}{l}\text { Bez lamaczy, } \\
\mathbf{z} \text { roletami }\end{array}$ & $\begin{array}{l}\text { Z lamaczami, } \\
\mathbf{z} \text { roletami }\end{array}$ \\
\hline Min & 36,27 & 37,56 & 35,43 & 36,57 \\
\hline Max & 78,85 & 80,26 & 78,76 & 80,23 \\
\hline Medium & 56,99 & 58,27 & 56,33 & 57,52 \\
\hline
\end{tabular}

Wilgotność we wnętrzu hali kształtuje się w całym okresie średnio na poziomie 57\%. Najwyższe jej wartości dochodzą do 80,26\% dla przypadku kiedy zastosowano łamacze światła na zewnątrz, bez rolet wewnętrznych.

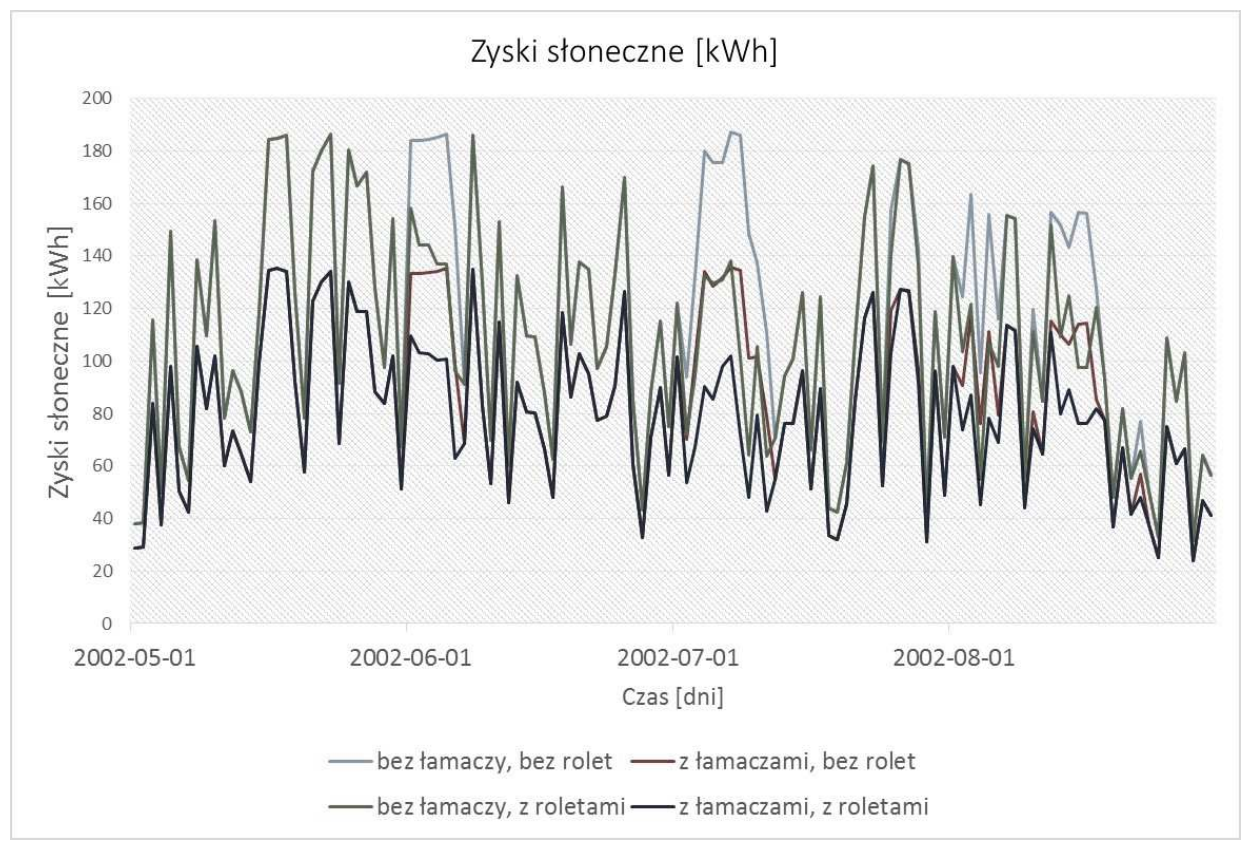

Rys. 7. Zyski słoneczne dla okresu analizy.

Fig. 7. Solar gains through external windows. 
Tabela 4. Średnie zyski energetyczne od promieniowania słonecznego i oświetlenia wewnętrznego

Table 4. Medium solar gains through external windows and general lighting profits for four simulation cases

\begin{tabular}{|l|c|c|c|c|}
\hline \multicolumn{1}{|c|}{ [kWh] } & $\begin{array}{l}\text { Bez łamaczy, } \\
\text { bez rolet }\end{array}$ & $\begin{array}{l}\text { Z łamaczami, } \\
\text { bez rolet }\end{array}$ & $\begin{array}{l}\text { Bez lamaczy, } \\
\mathbf{z} \text { roletami }\end{array}$ & $\begin{array}{l}\text { Z lamaczami, } \\
\text { z roletami }\end{array}$ \\
\hline $\begin{array}{l}\text { Zyski od } \\
\text { promieniowania }\end{array}$ & 117,73 & 108,23 & 108,23 & 79,25 \\
\hline $\begin{array}{l}\text { Zyski od } \\
\text { oświetlenia }\end{array}$ & 31,32 & 32,28 & 50,69 & 52,60 \\
\hline Zyski łącznie & 149,04 & 140,51 & 158,93 & 131,86 \\
\hline
\end{tabular}

Budynek, który nie posiada żadnych zabezpieczeń przeciwsłonecznych generuje zyski energetyczne średnio na poziomie $117,73 \mathrm{kWh}$ dziennie w ciągu czteromiesięcznego cyklu badawczego. Najmniejsze wartości niepożądanej $\mathrm{w}$ lecie energii słonecznej pozyskiwane są w przypadku zastosowania w obiekcie łamaczy światła oraz rolet wewnętrznych i wynoszą średnio 79,25 kWh.

Biorąc pod uwagę zyski energetyczne związane z potrzebą oświetlenia hali, najwięcej energii, 52,60 kWh, potrzeba w przypadku zastosowania zarówno rolet wewnętrznych jak i łamaczy na zewnątrz.

Rozpatrując łączne zapotrzebowanie od promieniowania i oświetlenia najmniej energii zużywa się $\mathrm{w}$ momencie zastosowania łamaczy światła i rolet wewnętrznych. Suma energii wynosi w tym wypadku 131,86 kWh.

\section{Wnioski}

Okres wysokich temperatur zewnętrznych oraz silnego nasłonecznienia jest niezwykle trudny do utrzymania komfortu cieplnego w obiektach pasywnych. Wyeksponowanie budynków o dużej powierzchni przeszkleń na działanie promieni słonecznych może skutkować przegrzewaniem. Istotne jest zatem racjonalne zastosowanie osłon w celu zapewnienia korzystnego mikroklimatu wewnątrz.

Z przeprowadzonych analiz wynika, iż z uwagi na warunki środowiskowe we wnętrzu hali najkorzystniejsze będzie zastosowanie zewnętrznych łamaczy światła, ale bez wewnętrznych rolet. Średnia wartość wskaźnika PMV dla takiego przypadku jest najniższa i wynosi 0,83 . Oznacza to, że warunki klimatyczne są najbliższe komfortowi cieplnemu. Ponadto maksymalna wartość wskaźnika przewidywanej oceny średniej równa się 1,98 i nie przekracza granicznej dla strefy komfortu wartości wynoszącej +/- 2,0. Dla pozostałych trzech wariantów symulacji wartości PMV przekraczały wspomniany próg, poza którym należy stosować metodę oceny obciążenia cieplnego. Służy ona do ustalenia obciążenia termicznego jako dającego się zaakceptować lub tolerować. 
Również wartości temperatur wewnątrz budynku są dla drugiego wariantu analizy najniższe, a maksymalna ich wartość wynosi $25,68^{\circ} \mathrm{C}$.

Wilgotność we wnętrzu hali wynosi średnio $57 \%$, a jej różnice dla poszczególnych wariantów są niewielkie. Przy założeniu wentylacji mechanicznej, charakterystycznej dla obiektów pasywnych, wartość ta jest satysfakcjonująca dla użytkownika obiektu.

Biorąc pod uwagę nadmierne zyski od promieniowania słonecznego najbardziej skuteczną metodą $\mathrm{w}$ ich ograniczeniu jest stosowanie łącznie rolet i łamaczy światła w okresach największego nasłonecznienia. Zyski słoneczne są w takim przypadku o około $30 \%$ mniejsze w stosunku do przegród przeszklonych bez zabezpieczeń słonecznych i wynoszą 79,25 kWh dziennie. Należy zwrócić jednak uwagę na to, że więcej energii potrzeba wówczas na oświetlenie hali co wiąże się również z generowaniem dodatkowych zysków cieplnych we wnętrzu. Łączne zapotrzebowanie na energię jest jednak i tak najmniejsze i wynosi w tym wypadku $131,86 \mathrm{kWh}$, a maksymalna temperatura równa się $26,87^{\circ} \mathrm{C}$.

Z punktu widzenia ekonomicznego, rolety wewnętrzne zwiększają o około $70 \%$ zapotrzebowanie na oświetlenie, jednak całkowite zyski słoneczne są najniższe gdy łączy sie je z łamaczami. Patrząc pod kątem komfortu termicznego, rolety wewnętrzne nie są pożądane. Dlatego zaleca się ich stosowanie, ale z odpowiednią kontrolą manualną, wyłącznie w okresach największego nasłonecznienia.

\section{Literatura}

[1] Fanger P.O., Komfort cieplny, Arkady, Warszawa, 1974.

[2] PN-EN ISO 7730:2006, Ergonomia środowiska termicznego. Analityczne wyznaczanie i interpretacja komfortu termicznego z zastosowaniem obliczania wskaźników PMV i PPD oraz kryteriów lokalnego komfortu termicznego.

[3] Rozporządzenie Ministra Infrastruktury w sprawie warunków technicznych jakim powinny odpowiadać budynki i ich usytuowanie.

[4] Tymkiewicz J., Systemy osłon przeciwsłonecznych - wady i zalety różnych rozwiązań, Czasopismo Techniczne 2-A/2/2011, Politechnika Krakowska.

\section{THE EFFECTIVENESS OF SUN PROTECTIONS IN THE FORMATION IN THE PASSIVE BUILDING USEFULNES PUBLIC}

\section{S u m m a r y}

The influence of sun protections was analysed in the article on the thermal comfort in the passive building of public usefulness. The comparisons of the conditions of the internal environment were executed in the studied object without the use of suitable protections and with the regard of roller blinds shading and overhangs. The summer period and he is unusually difficult to maintenance of the thermal comfort in passive objects. Exhibiting buildings about the 
large glasses surface on the working of sunny rays can have very negative results for the man. Profits from the being in the building sources of warmth, they can easily bring to overheating and shaking the thermal equilibrium of the organism in the connection with the high external temperature. The indication of the rational use of protections is the aim conducted analyses in the aim of the assurance of the profitable microclimate inside. The programme is the tool to the execution of the thermal analysis the Design Builder, making up interface to the simulating programme of buildings Energy Plus. He results from conducted analyses, that from the attention on environmental conditions in the use the most profitable will be to the interior of the hall both the external breakers of the light how and internal roller blinds. You should however pay the attention to this that byc left only in the moment of the large insolation, near the high temperatures of the external air should protections after the internal side.

Keywords: overhangs, blinds, PMV, solar gains

Przestano do redakcji: 25.11.2014 r.

Przyjęto do druku: 22.06.2015 r.

DOI:10.7862/rb.2015.34 